\title{
Profil Vertikal Logam Berat Tembaga (Cu), Nikel (Ni), Dan Mangan (Mn) di Core Sedimen Perairan Pantai Marunda, Teluk Jakarta
}

\author{
Kresna Rangga Darmansyah1, Sri Yulina Wulandari1*, Jarot Marwoto' dan \\ Endang Supriyantini²
}

\begin{abstract}
'Departemen Oseanografi, Fakultas Perikanan dan Ilmu Kelautan, Universitas Diponegoro 2Departemen IImu Kelautan, Fakultas Perikanan dan IImu Kelautan, Universitas Diponegoro Jl. Prof. H. Soedharto, SH, Tembalang, Semarang. 50275.

Email: yulina.wuland@gmail.com
\end{abstract}

\begin{abstract}
Vertical Profiles of Copper (Cu), Nickel (Ni) and Manganese (Mn) Heavy Metals of Sediments Cores in Marunda Coast Waters, Jakarta Bay
\end{abstract}

Heavy metals contained in the waste enter to the Marunda coastal waters in Jakarta Bay through the Tiram river, come from the Jabodetabek region which is an industrial and residential area. They will be deposited and accumulated in the bed sediments and potentially to cause contamination in the waters as well. The study was conducted to investigate vertical profiles of heavy metals $\mathrm{Cu}, \mathrm{Ni}$, and $\mathrm{Mn}$ based on sediment depth and the correlation between the concentration of heavy metals and the grain size of sediments. Coring method was used for sampling the sediments at $1-3 \mathrm{~cm}, 4-6 \mathrm{~cm}$ and $7-9 \mathrm{~cm}$ of depths. Samples were analyzed using AAS method to determine $\mathrm{CU}, \mathrm{Ni}$, and Mn concentrations. Sieving and pipetting methods were used to determine the grain size of the sediments. The results showed that the average concentration of heavy metals $\mathrm{Cu}, \mathrm{Ni}$, and $\mathrm{Mn}$ in the top layer was $7.74 \mathrm{ppm} ; 8.17 \mathrm{ppm} ; 1345.03 \mathrm{ppm}$. The middle layer was 6.91 ppm; 7.48 ppm; 1279.35 ppm. The bottom layer was 7.36 ppm; 7.79 ppm; 1413.66 $\mathrm{ppm}$. The concentration of Cu heavy metal had a positive correlation with the sand fraction, while the heavy metals $\mathrm{Ni}$ and $\mathrm{Mn}$ had a positive correlation with the mud fraction.

Keywords : Vertical profile, Heavy Metals, Sediment, Marunda Coast Waters

\begin{abstract}
Abstrak
Logam berat yang terkandung dalam limbah masuk ke perairan pantai Marunda di Teluk Jakarta melalui sungai Tiram, berasal dari daerah Jabodetabek yang merupakan kawasan industri dan pemukiman. Logam berat tersebut akan mengendap dan terakumulasi di sedimen dasar perairan dan berpotensi menimbulkan pencemaran perairan. Penelitian ini bertujuan untuk mengetahui profil logam berat Tembaga, Nikel, dan Mangan secara vertikal berdasarkan kedalaman sedimen dan korelasi antara konsentrasi logam berat dengan ukuran butir sedimen. Pengambilan sampel sedimen dilakukan menggunakan metode coring untuk kedalaman $1-3 \mathrm{~cm}$, 4-6 cm, dan 7-9 cm. Selanjutnya sampel sedimen dianalisis menggunakan metode AAS untuk mengetahui konsentrasi logam berat $\mathrm{Cu}$, Ni, dan Mn. Metode sieving dan pipetting digunakan untuk mengetahui ukuran butir sedimen. Nilai konsentrasi rata-rata logam berat $\mathrm{Cu}$, Ni, dan $\mathrm{Mn}$ pada lapisan atas untuk setiap stasiun berurutan sebesar 7,74 ppm; 8,17 ppm; 1345,03 ppm. Lapisan tengah sebesar 6,91 ppm; 7,48 ppm; 1279,35 ppm. Lapisan bawah sebesar 7,36 ppm; 7,79 ppm; 1413,66 ppm. Konsentrasi logam berat Cu mempunyai korelasi positif terhadap fraksi pasir, sedangkan logam berat $\mathrm{Ni}$ dan Mn mempunyai korelasi positif terhadap fraksi lumpur.
\end{abstract}

Kata kunci : Profil vertikal, Logam Berat, Sedimen, Perairan Pantai Marunda 


\section{PENDAHULUAN}

Peningkatan aktivitas industri dan jumlah penduduk di suatu daerah biasanya diikuti dengan pertambahan jumlah limbah, baik berupa limbah padat, cair maupun gas (Emery, et al., 1972). Demikian halnya dengan kawasan perairan pantai Marunda. Sungai Tiram menjadi jalur transportasi limbah sisa aktivitas industri dan aktivitas manusia lainnya yang berasal dari daerah Jabodetabek yang masuk ke perairan Teluk Jakarta. Kawasan ini menjadi sumber masukan bahan pencemar ke perairan Marunda. Ekosistem muara dan pesisir ini menjadi penting karena menampung kontaminan yang bersifat persisten yang terakumulasi di sedimen dasar perairan maupun organisme. (Palar, 1994, Alyazichi et al., 2015). Teluk Jakarta dan sekitarnya termasuk dalam paparan Sunda dengan kedalaman air laut sekitar 30 meter. Perairan ini merupakan perairan teluk yang tingkat pencemarannya paling tinggi di Asia. Pencemaran tersebut bahkan telah meluas sampai ke perairan Pulau Seribu (Edward, et al., 2004).

Limbah dari aktivitas industri umumnya mengandung bahan pencemar yang berbahaya seperti logam berat (Palar, 1994). Di samping bersumber dari aktivitas antropogenik atau industri, logam berat di lingkungan perairan dapat pula berasal dari proses alam (Kobielska et al., 2017). Logam berat yang masuk ke kolom air dari suatu perairan, biasanya akan segera tertransport ke dalam sedimen (Gu, et al., 2016). Jumlah logam berat yang terkandung dalam limbah akan bertambah tergantung jenis aktivitas industri maupun aktivitas manusia lainnya (Lestari dan Budiyanto, 2013). Adapun faktorfaktor yang mempengaruhi konsentrasi dan jenis senyawa logam berat di perairan adalah faktor kimia seperti $\mathrm{pH}$, faktor biologi seperti kehidupan organisme, faktor fisika seperti pengenceran, evaporasi, dan proses adsorbsi dari sedimen atau bahan organik dan anorganik (Kobielska et al., 2017). Berdasarkan jenis industri yang beraktivitas di sekitar kawasan aliran sungai Tiram, maka dapat diduga jenis logam berat yang terkandung dalam limbah industri atau aktivitas manusia yang berpotensi menimbulkan pencemaran. Dalam penelitian ini, logam berat yang dimaksud adalah tembaga (CU), nikel (Ni), dan mangan (Mn). Ketiga unsur tersebut termasuk logam berat esensial yang dalam jumlah tertentu masih dibutuhkan oleh organisme hidup, akan tetapi akan menimbulkan efek racun (toksik) jika terdapat dalam jumlah berlebihan dalam tubuh organisme hidup (Palar, 1994 dan Sosrosumihardjo, 2010). Logam berat tersebut lebih banyak berikatan dengan fraksi sedimen yang berukuran halus (Maslukah, 2013). Warni, et al. (2017) menyatakan, logam berat bersifat mengikat partikel lain yang mudah terikat pada sedimen dengan ukuran butir yang lebih kecil sehingga kemudian akan terendapkan di permukaan sedimen dalam perairan. Proses tersebut menyebabkan konsentrasi logam berat pada sedimen lebih besar dibandingkan dalam kolom airnya. Besaran konsentrasi logam berat yang terdapat setiap lapisan kedalaman sedimen (core) dapat menunjukan adanya masukan dan proses akumulasi yang terjadi pada sedimen (Li, et al., 2012; Al-Mur, et al., 2017).

Oleh karena itu dengan melakukan penelitian ini diharapkan bisa mengetahui profil vertikal logam berat $\mathrm{Cu}$, Ni dan $\mathrm{Mn}$ pada sedimen yang ditinjau dari besaran konsentrasi logam beratnya, berdasarkan kedalaman sedimen dasar perairan Pantai Marunda serta korelasi antara konsentrasi logam berat dengan ukuran butir sedimennya.

\section{MATERI DAN METODE}

Sebanyak empat stasiun penelitian (Gambar 1) sebagai lokasi pengambilan sampel sedimen yang ditentukan secara purposif (pertimbangan tertentu). Stasiun 1 dan 2 mewakili lokasi yang jauh dari sumber masukan logam berat yaitu muara sungai Tiram. Stasiun 3 dan 4 merupakan lokasi yang dekat jaraknya dengan muara sungai, serta dekat dengan aktivitas pariwisata dan lalu lintas kapal nelayan. Sampel sedimen diambil dengan menggunakan metode coring, yaitu menggunakan alat pipa polyvinylchloride (PVC) dengan diameter 3 inci dan panjang $60 \mathrm{~cm}$. Pipa dimasukkan dari permukaan sedimen dasar secara vertikal sampai kedalaman sedimen $9 \mathrm{~cm}$ di setiap stasiun. 


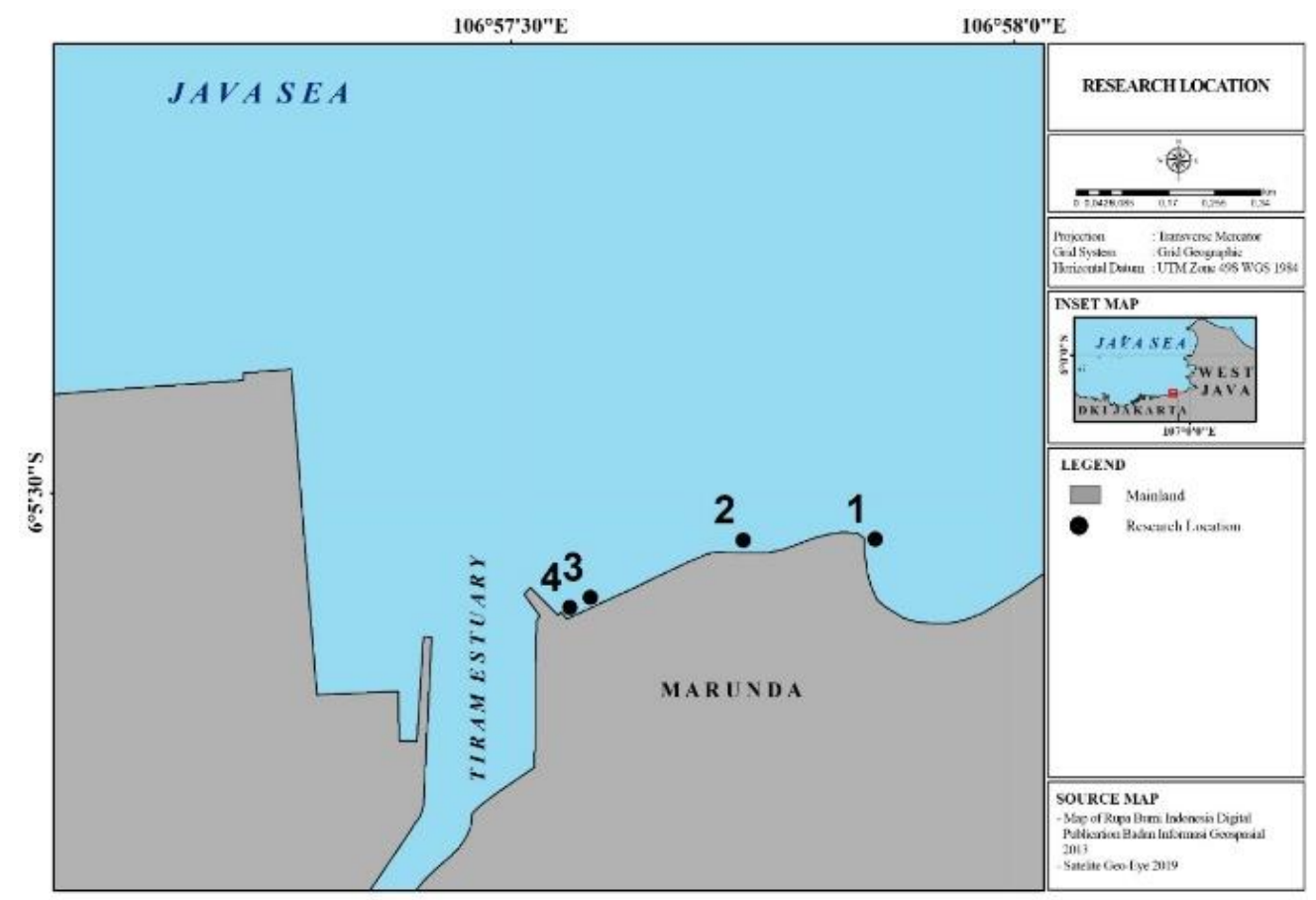

Gambar 1. Peta Lokasi titik Sampling di Pantai Marunda, Teluk Jakarta

Sedimen akan terperangkap dalam pipa tersebut (Gu and Lin, 2016; Zhu et al., 2019, Nazneen et al., 2019). Sedimen yang terambil dipisahkan dalam tiga lapisan secara vertikal yaitu lapisan atas (top layer) untuk kedalaman 1-3 cm, lapisan tengah (middle layer) kedalaman 4-6 cm, lapisan bawah (bottom layer) kedalaman 7-9 cm (Zhu et al., 2019). Pemisahan sedimen dilakukan dengan cara memotong setiap pipa berisi sedimen menjadi tiga bagian, sesuai kedalaman sedimen (Wang et al., 2012). Sampel sedimen selanjutnya dianalisis di laboratorium untuk mengetahui konsentrasi logam beratnya. Analisis konsentrasi logam berat menggunakan metode American Standard for Testing Material (ASTM) D 3974-81 dengan alat Atomic Absorption Spectrophotometer atau AAS (Hutagalung, 1995). Adapun analisis ukuran butir sedimen menggunakan metode sieving dan pipetting (Eleftheriou and Mclntyre, 2005). Pada analisis Ukuran butir kemudian dilanjutkan penamaan sedimen dengan menggunakan klasifikasi Sheppard (Mclntyre and Holme,1984; Liang, et al., 2019).

\section{HASIL DAN PEMBAHASAN}

Nilai konsentrasi rata-rata logam berat Cu, Ni,dan Mn pada lapisan atas setiap stasiun berurutan sebesar 7,74 ppm; 8,17 ppm; 1345,03 ppm. Lapisan tengah sebesar 6,91 ppm; 7,48 ppm; 1279,35 ppm. Lapisan bawah sebesar 7,36 ppm; 7,79 ppm; 1413,66 ppm. Secara keseluruhan data konsentrasi logam berat $\mathrm{Cu}, \mathrm{Ni}$, dan $\mathrm{Mn}$ dari hasil analisa laboratorium tersaji pada Tabel 1.

Berdasarkan hasil analisis ukuran butir sedimen, terdapat dua jenis sedimen di sedimen dasar perairan pantai Marunda, yaitu, pasir dan pasir lanauan. Adapun hasil dari analisis ukuran butir pada setiap stasiun dan kedalaman tersaji pada Tabel 2. Besaran konsentrasi logam berat $\mathrm{Cu}, \mathrm{Ni}$, dan $\mathrm{Mn}$ dari hasil penelitian menunjukkan nilai yang bervariasi terhadap kedalaman sedimen (Gambar 2). Perubahan besaran konsentrasi masing-masing logam berat pada setiap lapisan sedimen memberikan pola yang berbeda. Terdapatnya variasi besaran konsentrasi diduga karena adanya proses akumulasi dan pengendapan serta sumber masukan logam berat yang berbeda-beda. Proses akumulasi dan pengendapan logam berat di permukaan sedimen juga tergantung sifat kimia logam berat itu sendiri di perairan. Hal ini sesuai dengan pernyataan Al-Mur et al. (2017), bahwa konsentrasi logam berat di sedimen dipengaruhi perbedaan sifat logam berat yang berkaitan dengan 

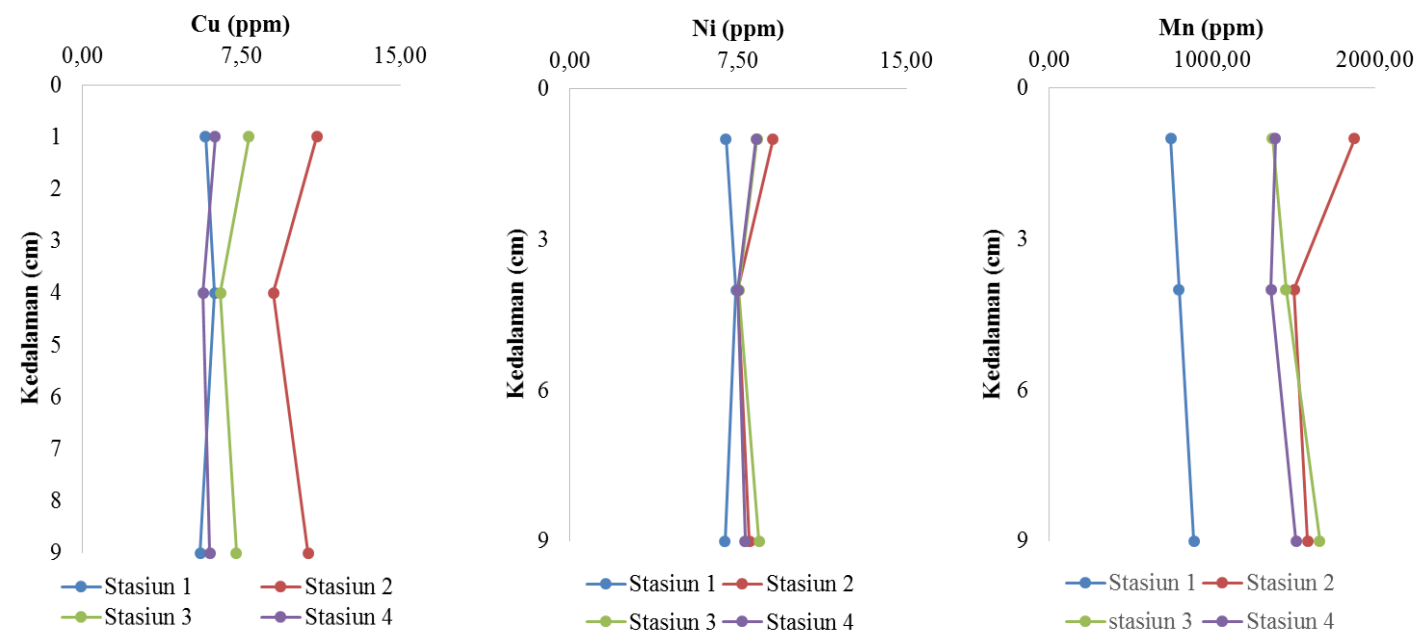

Gambar 2. Profil vertikal konsentrasi logam berat di sedimen

Tabel 1. Konsentrasi Logam Berat Cu, Ni, Mn

\begin{tabular}{cccccc}
\hline Logam & Kedalaman Sedimen & \multicolumn{4}{c}{ Konsentrasi (ppm) } \\
\cline { 3 - 5 } Berat & $(\mathrm{cm})$ & Stasiun 1 & Stasiun 2 & Stasiun 3 & Stasiun 4 \\
\hline \multirow{3}{*}{ Cu } & $1-3$ & 5,81 & 11,06 & 7,84 & 6,25 \\
& $4-6$ & 6,24 & 9,01 & 6,51 & 5,68 \\
& $7-9$ & 5,55 & 10,04 & 7,25 & 6,00 \\
& Rata-rata & 5,87 & 10,24 & 7,25 & 6,00 \\
$\mathrm{Ni}$ & $1-3$ & 6,96 & 9,06 & 8,35 & 8,31 \\
& $4-6$ & 7,41 & 7,50 & 7,53 & 7,49 \\
& $7-9$ & 6,91 & 8,01 & 8,44 & 7,81 \\
& Rata-rata & 7,09 & 8,19 & 8,11 & 7,87 \\
$\mathrm{Mn}$ & $1-3$ & 746,25 & 1873,00 & 1371,88 & 1389,00 \\
& $4-6$ & 796,00 & 1504,38 & 1455,00 & 1362,50 \\
& $7-9$ & 889,38 & 1588,00 & 1661,25 & 1516,00 \\
& Rata-rata & 810,54 & 1655,13 & 1496,04 & 1422,50 \\
\hline
\end{tabular}

Tabel 2. Ukuran Butir dan Jenis Sedimen

\begin{tabular}{cccccc}
\hline Stasiun & Kedalaman $(\mathrm{cm})$ & \% Pasir & \% Lanau & \% Lempung & Jenis sedimen \\
\hline \multirow{2}{*}{1} & $1-3$ & 92,69 & 5,81 & 1,50 & Pasir \\
& $4-6$ & 94,72 & 4,32 & 0,97 & Pasir \\
& $7-9$ & 93,38 & 5,34 & 1,27 & Pasir \\
\hline \multirow{2}{*}{2} & $1-3$ & 90,33 & 8,99 & 0,67 & Pasir \\
& $4-6$ & 92,55 & 7,38 & 0,08 & Pasir \\
& $7-9$ & 85,79 & 12,30 & 1,91 & Pasir \\
\hline \multirow{2}{*}{3} & $1-3$ & 76,16 & 20,84 & 3,00 & Pasir \\
& $4-6$ & 71,17 & 24,30 & 4,53 & Pasir lanauan \\
& $7-9$ & 67,77 & 30,88 & 1,35 & Pasir lanauan \\
\hline \multirow{2}{*}{4} & $1-3$ & 73,92 & 17,69 & 8,39 & Pasir lanauan \\
& $4-6$ & 80,11 & 18,27 & 1,62 & Pasir \\
& $7-9$ & 70,86 & 23,55 & 5,59 & Pasir lanauan \\
\hline
\end{tabular}


proses kimia seperti penggabungan senyawa maupun reaksi pertukaran ion.

Pada penelitian ini, apabila ditinjau dari stasiun pengambilan sampel, konsentrasi logam berat baik $\mathrm{CU}, \mathrm{Ni}$ maupun $\mathrm{Mn}$ mempunyai nilai tinggi pada lapisan atas (Tabel 1 dan Gambar 2), kemudian terjadi penurunan konsentrasi pada lapisan tengah dan kembali meningkat pada lapisan bawah. Besaran konsentrasi logam berat pada setiap lapisan sedimen menunjukkan adanya proses akumulasi logam berat. Yaitu, dimulai dari masuknya limbah yang mengandung logam berat ke perairan, termasuk run off dari daratan (melalui jalur sungai) yang selanjutnya akan mengendap di sedimen dasar perairan. Hal tersebut sesuai pernyataan Lie et al., (2012) dan Wang et al., (2012), bahwa keberadaan logam berat di sedimen dasar merupakan akibat proses akumulasi dan pengendapan logam berkaitan dengan tingkat aktivitas antropogenik di perairan. Di nyatakan pula oleh Cho et al. (2015), bahwa konsentrasi logam berat meningkat seiiring dengan berkurangnya kedalaman sedimen. Besaran konsentrasi logam berat di lapisan sedimen lebih tinggi sesuai dengan meningkatnya input polutan dan waktu aktivitas antropogenik (Cho et al., 2015).

Rata-rata nilai konsentrasi logam berat $\mathrm{Cu}, \mathrm{Ni}$, dan $\mathrm{Mn}$ pada stasiun 2 adalah yang tertinggi (Tabel 1). Posisi stasiun 2 ini berada cukup jauh dari sumber masukan (sungai).
Kondisi perairan pada lokasi ini merupakan yang relatif paling tenang. Diduga kondisi seperti ini yang menyebabkan logam berat yang berada di kolom air dapat terendapkan di permukaan sedimen. Ditambahkan oleh Rochyatun dan Rozak (2007), Wulandari et al. (2009), Lestari dan Budiyanto (2013), bahwa adanya proses resuspensi, mengakibatkan lambatnya proses pelarutan (disolusi) logam berat dari partikel tersuspensi sehingga konsentrasi logam berat di sedimen cenderung tinggi.

Tabel 1 menunjukkan bahwa logam berat $\mathrm{Mn}$ memiliki nilai konsentrasi yang jauh lebih besar dibandingkan dengan logam berat $\mathrm{Cu}$ dan Ni. Hal ini diduga karena sumber logam berat $M n$ yang secara alami memiliki kandungan yang tinggi di tanah (sedimen), selain masukan dari aktivitas manusia di daratan. Sebagaimana yang dinyatakan oleh Mengel dan Kirkby (1982) dan Lie et al. (2012), bahwa aktivitas antropogenik mempengaruhi tingkat konsentrasi logam berat di sedimen dasar perairan.

Gambar 3 menunjukkan, regresi linier antara konsentrasi logam berat dengan sedimen pasir memberikan korelasi positif dengan logam berat $\mathrm{Cu}(r=0,209)$, serta korelasi negatif dengan terhadap logam berat $\mathrm{Ni}(r=-0,405)$ dan $\mathrm{Mn}(r=-0,497)$. Adapun pada Gambar 4, sedimen lumpur (lanau dan lempung) memiliki korelasi negatif terhadap logam berat $\mathrm{Cu}(r=-0,179)$ dan
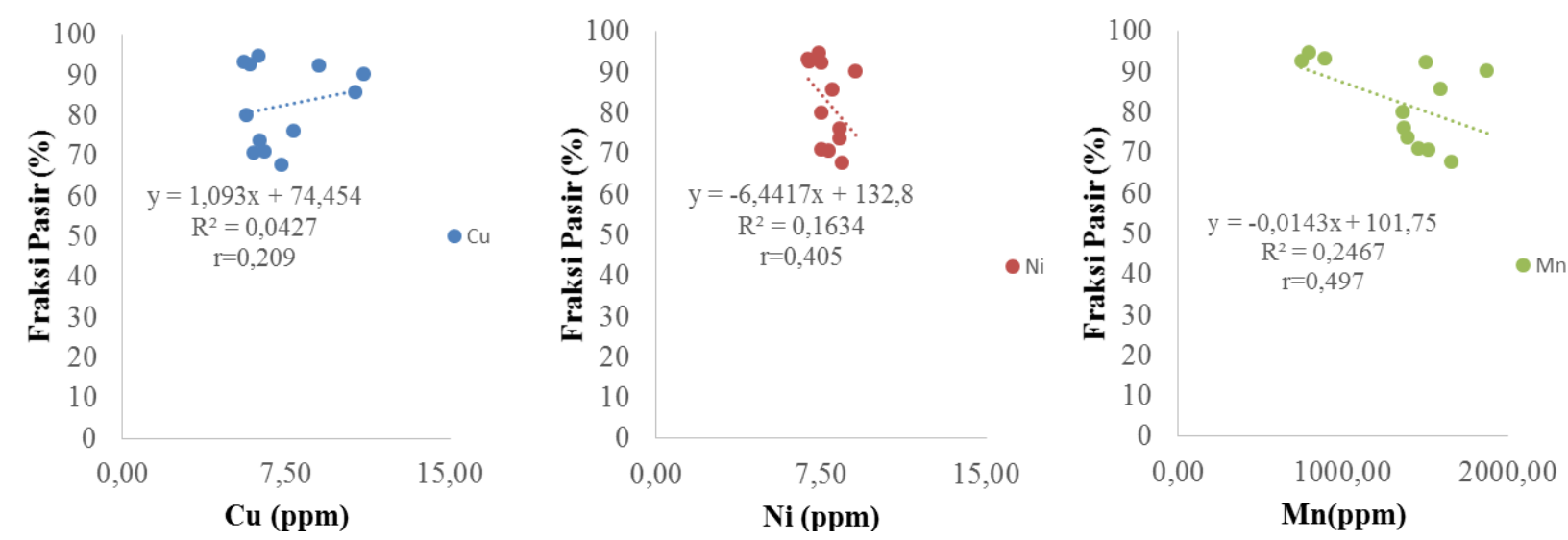

Gambar 3. Hubungan antara konsentrasi logam berat dengan fraksi pasir di sedimen 

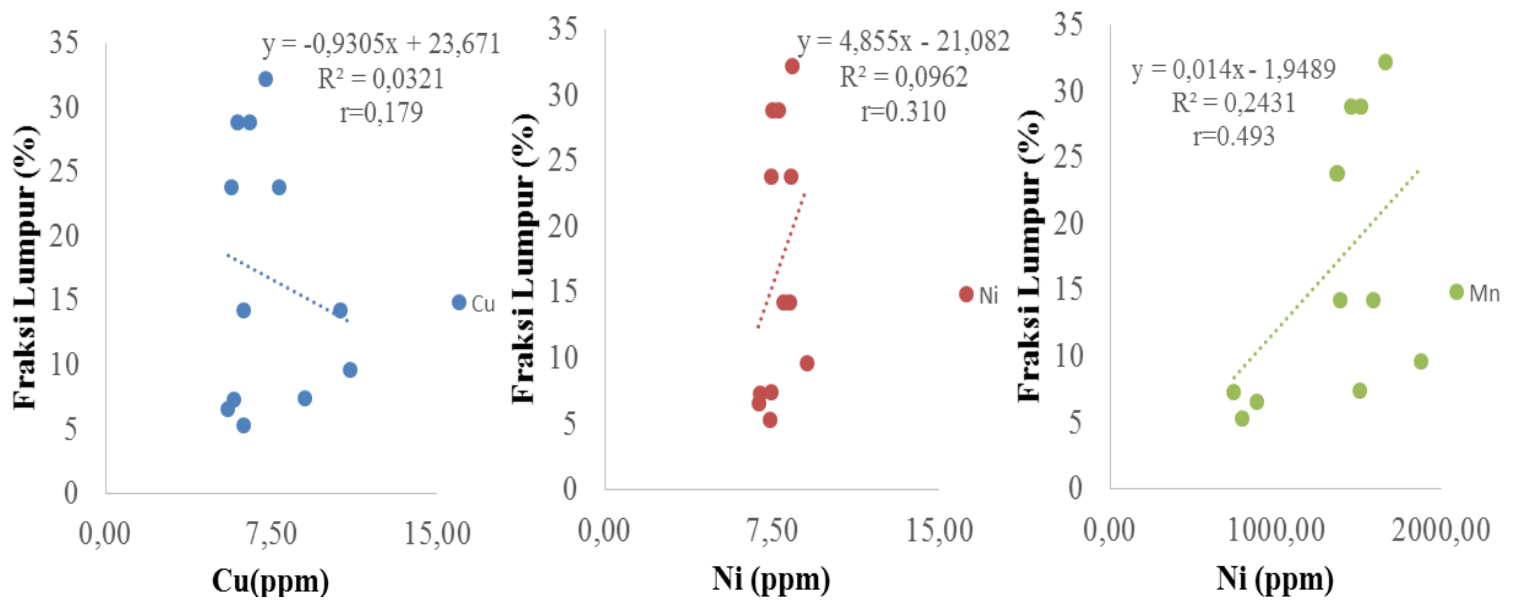

Gambar 4. Hubungan antara konsentrasi logam berat dengan fraksi lumpur (lanau dan lempung) di sedimen

korelasi terdapat korelasi positif terhadap Ni ( $r$ $=0,310)$ dan $M n(r=0,493)$. Ukuran butir pada sedimen lumpur memiliki ukuran yang lebih kecil atau halus dibandingkan dengan sedimen pasir. Partikel sedimen dengan ukuran butir yang kecil (halus) lebih banyak mengadsorbsi dan mengakumulasi logam berat (Liang, et al., 2019). Partikel sedimen yang lebih kecil atau halus, mempunyai luas permukaan yang lebih besar (dalam satuan bobot yang sama) dan kerapatan ion yang lebih stabil untuk mengikat logam dibandingkan dengan partikel sedimen yang berukuran lebih besar atau kasar (Maslukah, 2013).

\section{KESIMPULAN}

Profil vertikal logam berat dalam core sedimen ditinjau dari besaran konsentrasi rata-rata untuk logam berat $\mathrm{Cu}, \mathrm{Ni}$, dan $\mathrm{Mn}$ pada lapisan atas setiap stasiun berurutan sebesar 7,74 ppm; 8,17 ppm; 1345,03 ppm. Lapisan tengah sebesar 6,91 ppm; 7,48 ppm; 1279,35 ppm. Lapisan bawah sebesar 7,36 ppm; 7,79 ppm; 1413,66 ppm. Sedimen pasir memiliki korelasi positif terhadap logam berat Cu $(r=0,209)$ dan memiliki korelasi negatif terhadap logam berat $\mathrm{Ni}(r=-0,405)$ dan $\mathrm{Mn}$ $(r=-0,497)$. Sedimen lumpur (lanau dan lempung) menunjukkan korelasi negatif pada logam berat Cu ( $r=-0,179)$, sedangkan terhadap logam berat $\mathrm{Ni}(r=0,310)$ dan $\mathrm{Mn}(\mathrm{r}$ $=0,493$ ) menunjukan korelasi positif.

\section{DAFTAR PUSTAKA}

Al-Mur, B.A., Quicksall, A.N., \& AL-Ansari, A.M.A. 2017. Spatial and Temporal Distribution of Heavy metals in Coastal Core Sediments from The Red Sea, Saudi Arabia. Oceanologia. 59 (issue 3): 262270. doi : 10.1016/j.oceano.2017.03.003

Alyazichi, Y., Jones, B. \& McLean, E. 2015. Source Identification and Assessment of Trace Metals in Kogarah Bay, NSW, Australia. Environmental Monitoring Assessment. 187: 1-10. doi: 10.1007/s10661-014-4238-z

Badan Pusat Statistik. 2017. Kecamatan Cilincing Dalam Angka. BPS, Jakarta.

Cho, J., Hyun, S., Han, J.H., Kim, S. \& Shin, D.H. 2015. Historical Trend in Heavy Metal Pollution in Core Sediments from the Masan Bay, Korea. Marine Pollution Bulletin. 95(1): 427-432. doi : 10.1016/j.marpolbul. 2015.03.034

Doi: 10.1016/j.envpol.2011.12.041

Edward, Muhajir, \& Ahmad F. 2004. Akumulasi Logam Berat $\mathrm{Pb}, \mathrm{Cd}, \mathrm{Cu}, \mathrm{Zn}$ dan $\mathrm{Cr}$ dalam Sedimen Di Muara Sungai Cisadane, Ciliwung dan Citarum, Teluk Jakarta. Jurnal IImiah Sorihi. 3(1): 83-98.

Eleftheriou \& McIntyre, A. 2005. Method for the studi Marine Benthos. Blackwell Science Company Itd. USA. ISBN 0-63205488-3

Emery, K.O., Uchupi, E., Sunderland, J., Uktolseja, H.L., \& Young, E.M. 1972. 
Geological Structure and Some Water Characteristics of the Java Sea and Adjacent Continental Shelf. CCOP Technical Bulletin. 6:197-223.

GU, Y.G. \& Lin Q. 2016. Trace metals in Sediment Core from the Largest Mariculture base of the Eastern Guangdong Coast, South China: Vertical Distribution, Speciation and Biological Risk. Marine Pollution Bulletin. 113: 520525.

http://doi.org/10.1016/j.marpolbul.2016.0 8.029

Gu, Y.G., Wang, Z.H., LU, S.H., Jiang, S.J., Mu, D.H. \& Shu, Y.H. 2012. Multivariate Statistical and GIS-based Approach to Identify Source of Anthropogenic Impacts on Metallic Elements in Sediments from the mid Guangdong coasts, China. Environmental Pollution. 163:248-255.

Hutagalung, H.P. 1995. Penentuan Kadar Logam Berat. LIPI-Jakarta

Kobielska, P.A., Howarth, A.J., Farha, O.K., \& Nayak S. 2017. Review: Metal-Organic Frameworks for Heavy Metal Removal from Water. A School of Chemistry and Biosciences, Faculty of Life Sciences, University of Bradford, United Kingdom.

Lestari \& Budiyanto, F. 2013. Konsentrasi Hg, $\mathrm{Cd}, \mathrm{Cu}, \mathrm{Pb}$ dan $\mathrm{Zn}$ dalam Sedimen di Perairan Gresik. Jurnal Ilmu dan Teknologi Kelautan Tropis. 5(1): 182-191

Li, X., Liu, L., Wang, Y., Luo, G., Chen, X., Yang, X., Gao, B., \& Hu, X. 2012. Integrated Assesment of Heavy Metal Contamination in Sediments from a Coastal Industrial Basin, NE China. HMCCIA., 7(6): e39690. doi: 10.1371/jour nal.pone.0039690

Liang J., Liu J., XU G. \& Chen B. 2019. Distribution and Transport of Heavy Metals in Surface Sediments of The Zhejiang Nearshore Area, East China Sea: Sedimentary Environmental Effects. Marine Pollution Bulletin, 146: 542-551. doi : 10.1016/j.marpolbul.2019.07.001

Maslukah, L. 2013. Hubungan antara Konsestrasi Logam Berat $\mathrm{Pb}, \mathrm{Cd}, \mathrm{Cu}, \mathrm{Zn}$ dengan Bahan Organik dan Ukuran
Butirdalam Sedimen di Estuari banjir Kanal Barat, Semarang. Buletin Oseanografi Marina. 2:55-62.

Mc Intyre, N.D. \& Holme, M.G.. 1984. Methods for Study of Marine Benthos. Second edition. Blackwell Scientific Publication. Oxford.

Mengel, K. \& Kirkby, E.A. 1982. Principles of Plant Nutrition. International Potash Institute. Switzerland: 491-498.

Nazneen S., Singgh S. \& Raju N.J. 2019. Heavy Metal Fractionation in Core Sediments and Potential Biological Risk Assessment from Chilika Lagoon, Odisha State, India. Quaternary International. 507: 370-388. doi: 1016/j.quaint.2018.05.011

Palar, H. 1994. Pencemaran dan Toksikologi Logam Berat. PT Rineka Cipta, Jakarta.

Rochyatun, E. \& Rozak, A. 2007. Pemantauan Kadar Logam Berat dalam Sedimen di Perairan Teluk Jakarta. Makara Journal of Science. $11(1):$ 28-36

Sosrosumihardjo, D. 2010. Mengenal Logam Beracun. PT. Gramedia, Jakarta.

Sugiyono. 2009. Metode Penelitian Kuantitatif, Kualitatif dan R\&D. Alfabeta, Bandung.

Wang, Y., Hu, J., Xiong K., Huang X. \& Duan S. 2012. Distribution of Heavy Metals in Core Sediment from Baihua Lake. Procedia Environmental Sciences . 16: 51-58

Warni, D., Karina, S., \& Nurfadillah, N. 2017. Analisis Logam Pb, Mn, Cu dan Cd pada Sedimen di Pelabuhan Jetty Meulaboh, Aceh Barat. Jur. IImiah Mahasiswa Kelautan dan Perikanan Unsyiah. 2(2): 246-253.

Wulandari, S.Y., Yulianto, B., Santosa, G.W. \& Suwartimah, K. 2009. Kandungan Logam berat $\mathrm{Hg}$ dan $\mathrm{Cd}$ dalam air, Sedimen dan Kerang Darah (Anada granossa) dengan menggunakan Metode Analisis Pengaktifan Neutron (APN). IImu Kelautan. 14(3):170-175.

Zhu, $H_{\text {., }}$ Bing, $H_{\text {., }}$ Wu, Y., Zhou, J., Sun, $H_{\text {., }}$ Wang, J. \& Wang, X. 2019. The Spatial and Vertical Distribution of Heavy Metal Contamination in Sediments of the Three Gorges Reservoir Determinated by AntiSeasonal Flow Regulation. Science of the Total Environment, 664:79-88. 